\title{
The Application of Three-Dimensional Visualization Technology in Village Information Service Platform
}

\author{
Xiaoxia Yang, Yong Liang, and Song Jia \\ School of Information Science and Engineering, \\ Shandong Agricultural University, \\ Taian, Shandong Province, P.R. China, 271018 \\ yangxx@sdau.edu.com
}

\begin{abstract}
Recently Three-Dimensional (3D) Visualization Technology has been widely used in several industries. This is about the application of 3D visualization technology into the construction of village information service platform. Because village has small scope of management, the existing large-scale 3D visualization technology can't be used in the construction of village information service platform. By the use of high-resolution remote sensing image and high precision DEM solve the problem of fine terrain. In the view of the situation that most town building are domestic architecture and they have the same appearance, research the technology of rapid model. Using the data obtain from high-resolution remote sensing image we can more quickly establish model. Use ShanDong Province DingZhuang village as a demonstration site, establish the 3D scene of DingZhuang village, that can be a good foundation of the establishing of village information service platform for DingZhuang.
\end{abstract}

Keywords: 3D visualization technology, sensing image, DEM.

\section{Introduction}

3D visualization includes two respects content: virtual reality and real[1] [2] [3], need comprehensive application of remote sensing and GIS, multimedia, network technology and virtual simulation [4] [5]. 3D visualization is an important part of rural informationization construction, and an important way to improve rural informationization management level. The existing large-scale 3D visualization technology can't be used in the construction of village information service platform: village management has small scope but need high precision, always need to every household. Thus research the rapid modeling technique based on rural is an important part of rural 3D visualization, and today's high-resolution remote sensing images and digital terrain model provides important support for modeling. Use ShanDong Province DingZhuang village as a demonstration site, discuss rapid modeling technique, found 3D scene, that can be a good foundation of the establishing of village information service platform for DingZhuang. 


\section{Rebuild the Scene Based on High-Resolution Remote Sensing Images and DEM}

The image-forming principle of remote sensing images is using camera vertical shooting the surveyed area from a high point [6], and using frame shoot method, finally all the frames will joined into one remote sensing image of the surveyed area. DEM is one of the data set of plane coordinates(x,y) and elevation(z) within a scope of regular grid, mainly used to describe the physiographic space distribution of the surveyed area. Combining remote sensing images and DEM can integrallty describe the $3 \mathrm{D}$ terrain characteristics.

For buildings, remote sensing images have the ground projection that like shows in Figure 1. After shooted by the camera, the polygon AA" B" C"'CD formed by add thick line is the building's projection on the ground. Therefore, we can divide the projection on the ground into two categories: vertical shooting and deflection shooting. For the vertical shooting, we can only get the building's width and length from remote sensing images, in order to elaborate modeling the buildings, we still need on-site measure the height of the building, create the result that this type of building's modeling must take even more time. For deflection shooting, we can fully use remote sensing image get width, length and height of the building, use the data get from the image we can rapid modeling.

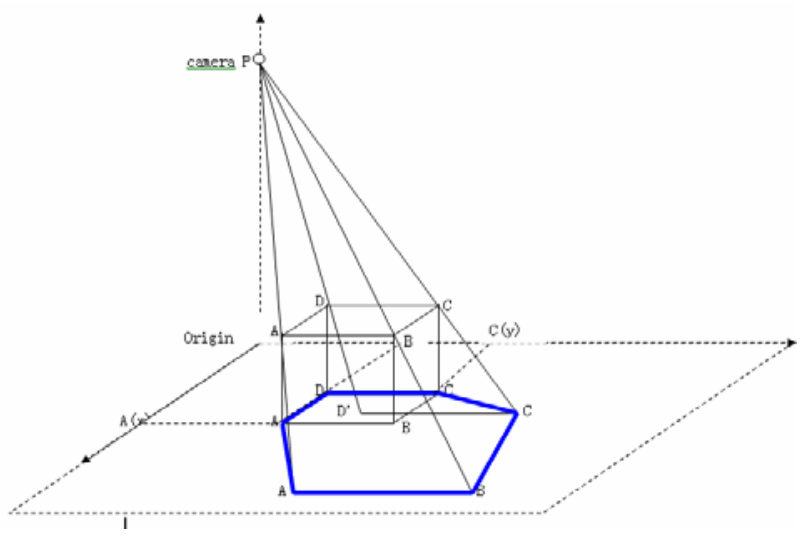

Fig. 1. Building's projection on the ground

\subsection{Restore the Camera's Position}

In order to restore the camera's position, we need on-site measure a deflection shooting building's data. Suppose that length $(\mathrm{AB})$ of the building $\left(\mathrm{ABCD}-\mathrm{A}^{\prime} \mathrm{B}^{\text {' }} \mathrm{C}^{\prime} \mathrm{D}^{\prime}\right)$ is $\mathrm{L}$, the width $(\mathrm{AD})$ of it is $\mathrm{W}$ and the height( $\left.\mathrm{AA}^{\prime}\right)$ is $\mathrm{H}$, the coordinate of the camera is $(0,0, \mathrm{Hp})$, thus we can restore the camera's position use the under formula:

$$
\frac{A^{\prime \prime} A}{A^{\prime \prime} A+A O}=\frac{\mathrm{H}}{H_{p}} \text {. }
$$




$$
\begin{gathered}
\frac{B^{\prime \prime} B}{B^{\prime \prime} B+B O}=\frac{H}{H_{p}} . \\
\frac{C^{\prime \prime} C}{C^{\prime \prime} C+C O}=\frac{H}{H_{p}} .
\end{gathered}
$$

Formula (1) is proved as follow:

$\because$ triangle $\mathrm{A}^{\prime} \mathrm{A}^{\prime \prime} \mathrm{A} \cong \mathrm{PA}{ }^{\prime \prime} \mathrm{O}$

$$
\therefore \frac{A^{\prime \prime} A}{A^{\prime \prime} A+A O}=\frac{H}{H_{p}}
$$

Formula (2), (3) is similar as (1), here no longer prove .

Further simplify and processing the formula:

$$
\begin{aligned}
& \frac{A^{\prime \prime} A}{A^{\prime \prime} A+A O}=\frac{B^{\prime \prime} B}{B^{\prime \prime} B+B O}=\frac{C^{\prime \prime} C}{C^{\prime \prime} C+C O} \\
= & \frac{A^{\prime \prime} A}{A^{\prime \prime} A+\sqrt{A^{2}(x)+A^{2}(y)}} \\
= & \frac{C^{\prime \prime} C}{C^{\prime \prime} C+\sqrt{C^{2}(x)+C^{2}(y)}} \\
= & \frac{A^{\prime \prime} A}{A^{\prime \prime} A+\sqrt{(B(x)-L)^{2}+B^{2}(y)}} \\
= & \frac{C^{\prime \prime} C}{C^{\prime \prime} C+\sqrt{B^{2}(x)+(B(y)+W)^{2}}}
\end{aligned}
$$

$\mathrm{A}(\mathrm{x})$ is the $\mathrm{x}$ axis distance from the building point $\mathrm{A}$ to the camera, $\mathrm{A}(\mathrm{y})$ is the $\mathrm{y}$ axis distance from the building point $B$ to the camera, then $B(x)=A(x)+L, B(y)=A(y)$, $\mathrm{B}(\mathrm{x})=\mathrm{C}(\mathrm{x}), \mathrm{B}(\mathrm{y})=\mathrm{C}(\mathrm{y})-\mathrm{W}$. A' $\mathrm{A}$ and $\mathrm{BB}$ " can be directly measured from remote sensing images. Thus we can get the distance from camera $\mathrm{P}$ to every point of the building, according to the coordinate of the building's point we can get the camera P's position.

\subsection{According to the Position of Camera P Get the Data of the Building}

This is the inverse process of restore the camera's position, we have get the position of camera $\mathrm{P}$ and measured data from remote sensing images, according to the formula (1),(2),(3), we can get every building's data. Because all the building's data can obtain from the image, we needn't on-site measure the buildings, so the modeling speed will be very quick. 


\subsection{Overlay DEM}

For real surveyed area, its physiographic characteristics is impossible unchangeable, after overlay DEM will make the surveyed area data more realistic.

\section{The Establish of Rural 3D Visualization}

Paper use ShanDong Province DingZhuang village as a demonstration site, discuss the method of rapid modeling. Rural 3D visualization system has its characteristics:

Village has small scope, usually dozens of square kilometers to one or two hundreds square kilometers, so rural 3D visualization has small amount of data.

Rural 3D visualization system not only used to browse, often need have the function of inquire. This prompt a higher require to the $3 \mathrm{D}$ visualization system, always need model in a even small unit, rural 3D visualization system need inquire precisely to every household or to every piece of paddy field.

Rural scene is different from city scene, most of the area is farmland, and most folk houses have the similar appearance. This is an important condition of rapid modeling.

According to the characteristics mentioned above, we can establish rural 3D visualization system follow under step:

1. Obtain high-resolution remote sensing image and high precision DEM of the village.

2. Overlay the remote sensing image and DEM.

3. On-site measure a building, restore the position of the camera.

4. Because village building has similar appearance, we can select typical building, according to the camera's position get its data, establish model, put them to the accurate position.

\section{Conclusion}

In order to achieve precise requirement, the existing process of modeling always need on-site measure, and establish model for every building. This leads to the result that there are lots of model and large amounts of data. At the same time because need onsite measure, the modeling speed will be very slow. This paper discuss how to use high-resolution remote sensing image and high precision DEM establish rural 3D visualization. First we restore the position of camera, then use the position of the camera obtain the data of deflection shooting building. In this way we save lots of time, greatly improves the speed of modeling.

\section{Acknowledgements}

This study has been funded by State Bureau of Surveying and Mapping. The project name is the construction and demonstration of village and town comprehensive information service Platform based on spatial data. It is supported by Shandong Agricultural University. Sincerely thanks are also due to Dingzhuang town for providing the data for this study. 


\section{References}

1. Aliage, D., et al.: MMR:An interactive massive model rendering system using geometric and image-based acceleration. In: ACM Symp on Interactive 3D Graghics, vol. 17, pp. 179-286 (1999)

2. Fang, M.: Studies on interactive rendering of huge 3D point-based models. Peking University, Beijing (2005)

3. Wei, H.: Fast rendering techiques for large-scale complex scene. ZheJiang University, ZheJiang (2003)

4. Fraser, C., Blatsavias, E.P., Gruen, A.: Geometric Potential and Suitability for 3D Building Reconstruction. Photogrammetrie-Fernerk-undung-Geoinformation, Geodaten Schaffen Verbindunge (2001)

5. Gruen, A.: Atotmation in Building Reconstruction. In: hotogrammetric Week 1997, vol. 7, pp. 168-174 (1997)

6. Baltsavias, E.P., Pateraki, M., Zhang, L.: Radiometric and Geometric Evaluation of lkonos Geoimages and Their Use for 3D Building Modeling. Publishing House of Wuhan Technical University of Survering and Mapping, WuHan (1998) 